\title{
Mozzie bites in the morning: The UN sustainable development goals in the Pacific
}

\section{Yvonne Te Ruki Rangi o Tangaroa Underhill-Sem}

Based on a keynote presentation to:

The convergence of evaluation and impact measurement

Annual Conference of the Aotearoa New Zealand Evaluation Association

Te Papa, Wellington, 19 July 2016

Kia orana kotou katoatoa, tēnā koutou, bula vinaka, namste, talofa lava, fakalofa lahi atu, malo e lelei, gud aftenun (Bislama), and warm greetings.

I acknowledge Ngāti Toa. ${ }^{1}$ I also acknowledge Ngati Akatauira of $\mathrm{Nga} \mathrm{Pu}$ Toru in the Cook Islands, and my ancestors from Niue, Germany, and England. I thank Shelly Rao and Tamasailau Suaalii from the Pasifika fono for inviting me to give this keynote address. They know that I have worked at the edges of research and evaluation in the Pacific for many years, and, like them, I am fascinated with what has happened there, what the challenges for the future are, and why it is imperative to be vigilant in addressing inequality and calling out the privilege of power. Finally, I acknowledge those 
whānau who have passed before me and whose spirits I know inhabit this place-especially my mother, Jasmine Underhill, who has tivaevae resting here in Te Papa.

\section{Introduction and positioning}

Cannons Creek in Porirua, Aotearoa New Zealand, is one of my tūrangawaewae. In the 1960s my parents left Rarotonga, Cook Islands, to provide a better education for their children. Cannons Creek became their home. Both were committed to raising a family in a community environment, which meant they got involved in building a community (Underhill-Sem, 2003). My mother was elected onto the Porirua City Council and served as Deputy Mayor for 12 years, from 1989 to 2001. From this family base, and with the education my parents sought for their six children, I have gone on to live and work in Papua New Guinea, Samoa, Bonn, Brussels, Canberra, and many other countries in the Pacific. Although my journey has its own particularities, it is not unlike the mobility journeys of many Pacific Islanders (e.g., see Bennett, 2015).

Since 2002, when I took a sedentary domestic turn, I have been based in central Auckland while teaching and undertaking research in development studies in the Faculty of Arts at the University of Auckland. My research and teaching, which keep me mobile, are best summed up in a recent paper entitled "Critical Gender Studies and International Development Studies: Interdisciplinarity, Intellectual Agility and Inclusion" (Underhill-Sem, 2016). My current research projects include examining an expanded notion of citizenship in peripheral markets in the Pacific; understanding the interlinkages between maternities and care economies in out-of-the-way places; interrogating the paradoxical place of labour mobility in Pacific labour markets; and contemplating flowers and their cultural meanings in the Pacific.

My academic work of teaching and research also provides 
opportunities to support the work of civil society in the Pacific and New Zealand, especially secular organisations with interests in eliminating the structural causes of poverty, addressing gender inequality, and co-producing local development solutions in the Pacific. This is facilitated by my role as co-chair of the Oxfam NZ Board, but also via the various consultancy projects with regional development organisations and civil society with which I have been involved. This kind of multisite and cross-disciplinary engagement requires being alert to global processes of development, like the defining and implementing of the United Nations Sustainable Development Goals (henceforth SDGs) adopted in 2015.

\section{The United Nations Sustainable Development Goals: What are they and why do they matter?}

The SDGs are a key part of the United Nations 2030 Agenda for Sustainable Development (United Nations, 2015c). Considerable effort has gone into developing the 17 SDGs, their 169 targets, and 230 indicators. The 17 SDGs are:

1. End poverty in all its forms everywhere.

2. End hunger, achieve food security and improved nutrition, and promote sustainable agriculture.

3. Ensure healthy lives and promote wellbeing for all at all ages.

4. Ensure inclusive and equitable quality education and promote lifelong learning opportunities for all.

5. Achieve gender equality and empower all women and girls.

6. Ensure availability and sustainable management of water and sanitation for all.

7. Ensure access to affordable, reliable, sustainable and modern energy for all.

8. Promote sustained, inclusive and sustainable economic growth, 
full and productive employment, and decent work for all.

9. Build resilient infrastructure, promote inclusive and sustainable industrialisation, and foster innovation.

10. Reduce inequality within and among countries.

11. Make cities and human settlements inclusive, safe, resilient and sustainable.

12. Ensure sustainable consumption and production patterns.

13. Take urgent action to combat climate change and its impacts (taking note of agreements made by the United Nations Framework Convention on Climate Change (UNFCCC) forum).

14. Conserve and sustainably use the oceans, seas and marine resources for sustainable development.

15. Protect, restore and promote sustainable use of terrestrial ecosystems, sustainably manage forests, combat desertification and halt and reverse land degradation, and halt biodiversity loss.

16. Promote peaceful and inclusive societies for sustainable development, provide access to justice for all and build effective, accountable and inclusive institutions at all levels.

17. Strengthen the means of implementation and revitalise the global partnership for sustainable development.

In the lead-up to the launch of the SDGs, and since then, there was considerable commentary from a range of stakeholders-including scholars, policy makers, donors and governments — on the value and use of the SDGs. The UN made unprecedented attempts to ensure open and participatory consultation and debate via various mechanisms: an interactive online open consultation on "The World We Want" (The World We Want, 2015), which informed the Open Working Group in 2014; the establishment of nine Major Groups 
and Other Stakeholders forums (United Nations, 2015a); and the ongoing High Level Political Forum (United Nations, 2015b). For policy makers, researchers, and evaluators, the processes of measuring progress against the SDGs present both challenges and opportunities in the Pacific and in Aotearoa New Zealand.

Valid scepticism about the value of global goals abounds, but they are here to stay. This means it is important to connect the focused technical work that goes into assessing the progress made towards such goals with the broader moral imperative to ensure that we "leave no-one behind"-the captivating commitment made by all countries of the UN at the launch of Agenda 2030 in 2015. In this paper I ask, How are we going to do this in the Pacific? and Where first? Development needs in the Pacific are interlinked and pressing, reliable data are in short supply, and, more importantly, local understanding of progress, wellbeing and justice is as diverse as the over 1,000 languages in the region.

To foreshadow my conclusion, I argue that as we move into this space we need to be progressively creative when the universally specified data are not there. This means we need to construct data ethically by working in partnership with the people the data refer to. We need to be technically brave. This means we need to be informed by interrogating accessible data even further, by using technology well, and by working respectfully with new partners. Underlying this is the need to understand notions of ethical practice that go beyond bureaucratic 'ethics creep', and to vigilantly ask, Who does what, where, and with what quality assessment?

I am sure that under the SDG framework the demand for evaluation and monitoring will grow. As 'professionals' working in a neoliberal economic world, our expertise, prestige, and credibility are not only easily accrued but also seldom questioned. So, we need to ensure that unethical practice is effectively tackled so that the resources 
needed to address inequality and poverty are available.

Economic and social inequality and exclusion in Aotearoa New Zealand and the Pacific continue to grow. Despite good and careful planning, we are often caught off-guard by the scale and depth of domestic violence, generational poverty, and gender inequality. So although we might take good care by using insect repellent and taking malaria prophylaxis, we might (and many times do) still wake up in the morning with 'mozzie bites'. This may be, as is often the case, just an irritation, but in some parts of the world, and throughout the Pacific, a mozzie bite in the morning - or at any time now_can lead to debilitating long-lasting diseases such as malaria, dengue, chikungunya and, more recently, zika.

Underlying any approach to evaluation in the context of SDGs is a question about knowledge: what knowledge are we privileging in our evaluation questions, and why? In international development, evaluation involving well-informed dialogue with multiple stakeholders, and careful data-gathering and interpretation methods, should be the norm. In this way, collisions of incompatible world views can be avoided and innovative ways of learning and new insights can emerge.

\section{First a story...}

In November 2012 a 20-year-old high school student called Melia (my niece) was admitted to a provincial hospital in Papua New Guinea (PNG). She had fainted when she was sitting her last exams because of "loss of blood" during her monthly menstrual bleed. She had had a disrupted high school education because of floods, which had destroyed access to her boarding school for 2 years in a row. The floods destroyed the gardens needed to feed about 400 students in the boarding school. Melia was a promising and hardworking student and was determined to complete her education even if it 
meant having to go to a boarding school many kilometres from her home. She was determined to complete her education without adding further burdens to her family, who were semisubsistence farmers. During the school holidays she earned pocket money by selling the peanuts she had planted.

After about a week of hospital care she returned with her mother to her home village about 150 kilometres away. Two months later, after another heavy monthly bleed, Melia died. She died in the local health subcentre, lying in the arms of her father and surrounded by many members of her family.

This story emphasises the interrelated nature of tragedy in the Pacific. It poignantly shows the context of development in the Pacific: young people want education and jobs, and they and their families are prepared to be mobile to gain access to education and health care, but there is a gendered component that is always present but often considered too raw or culturally awkward to be openly spoken of and addressed, and is thus silenced.

Melia's death was tragic in many ways, beginning with the fact that it was preventable. She was not the only one in that school who died that year in that way. This highlights the significant gender-related problems in health care access and delivery for young menstruating women in residential high schools in PNG. It also raises issues relating to the ubiquitous environmental transformations that are ever present in the Pacific due to modifications in land use, exacerbated by unquestionable changes in climate. Add to this situation the dynamic way in which cultural practice and religious beliefs contribute to the dilemmas faced by people as they seek to find answers to tragedies caused by these development transformations.

In the case of Melia's tragic death all these factors are interlinked. When trying to retrospectively diagnose the cause of Melia's death we cannot just look to the state of her young, apparently healthy, 
menstruating female body for answers. We must also look to the education system and ask why iron-rich food was not provided all year round. And to the health system: why was she allowed to return to her village, which was far away from a well-stocked health centre? And to her parents: why were they silent about her 'condition'? Why did they prefer to just pray for an intervention?

In the Pacific, the evaluation of any programme or project must be understood in this wider interlinked context, and it must be able to accommodate multiple and differing ways of understanding wellbeing and causation. Addressing these interlinked issues requires consideration of at least four of the UN SDGs:

- SDG 3 Ensure healthy lives and promote wellbeing for all at all ages

- SDG 4 Ensure inclusive and equitable quality education and promote lifelong learning opportunities for all

- SDG 5 Achieve gender equality and empower all women and girls

- SDG 13 Take urgent action to combat climate change and its impacts.

Clearly it is not an easy task.

\section{Opportunities for progressive evaluation}

This leads me to my first, hopeful, point about opportunities for the progressive evaluation of development in the Pacific. In Aotearoa New Zealand we are moving slowly but steadily in the right direction to a more inclusive understanding of how to integrate diverse world views into everyday practice. As widespread commitment to the principles of the Treaty of Waitangi settles further into our daily, personal, and professional practice, there are fewer ways to avoid understanding how to work respectfully with indigenous peoples and world views. 
This presents a new understanding of the importance of indigeneity as an analytical concept.

Political development geographer Sarah Radcliffe (2015) makes a useful distinction between indigenous peoples and understandings of indigeneity. She argues that indigenous peoples "embody non-western culture-natures" and indigeneity refers to "the quality of being indigenous" (Radcliffe, 2015, p. 2). The value of this distinction is that we can move from relatively straightforward, objective categories of indigenous peoples to

their production through processual, multi-actor, multi-scalar networks and within specific grounded contexts, each with particular configurations of colonial histories, post-colonial modernities, epistemological-ontological commitments and formulations of difference. (Radcliffe, 2015, p. 2)

Indigeneity thus describes a kind of relationship rather than an objective fact-like indigenous people. It is a concept that focuses on the "social, cultural, economic, political, institutional, and epistemic processes through which the meaning of being Indigenous in a particular time and place is constructed" (Radcliffe, 2015, p. 2.) These times and places will change, from Te Upoko o te Ika in Aotearoa New Zealand to Oro Province in PNG. However, we can still focus on the relationships that indigeneity makes possible and, crucially, in the processes that allow for new forms of knowledge to be co-produced.

For instance, I was catching up with my daughter recently and sharing stories from our village in PNG. She was dismayed to learn that her younger cousins were no longer being taught in their local language because the education department cannot afford to pay to produce material for early childhood education in all the languages in the province. From a position in Aotearoa New Zealand, she felt strongly that without language, village life would change. 
In Aotearoa New Zealand and other parts of the Pacific where languages are being revived, this is a very important part of indigenous self-identification. However, we were reminded that 'back home' our family still know how to make a roof of palm leaves, they can still make sago to eat, they can still make gardens to feed everyone, and they still tell stories in the local language-funny, complex stories that include details about how people walk and talk and eat and smell. This is how indigeneity works: it allows for a focus on relationships-different relationships with different power dimensions. This is not to say that the apparent loss of language to power-laden processes of modern education is not something to resist, as argued for by my New Zealand-based daughter. Such resistance needs to happen, but alongside the people 'back home', not just by concerned family members living elsewhere.

I am encouraged that in Aotearoa New Zealand indigeneity prevails in many and various ways. In the Pacific, indigeneity also prevails, although care is needed in assuming any single overarching world view. From my experience living in the eastern and western Pacific, world views vary hugely. In the village in PNG where my family live, everyone speaks at least five languages. Each language carries with it slightly different ways of explaining wellbeing and causation, and these contrast significantly with people living in other parts of the country. PNG has 23 provinces (including one district and one autonomous region). This is like 23 countries on one large island. Each province is larger in size and population than most of the countries in the eastern Pacific.

So, the progressive insight I want to offer is: take advantage of diverse understanding of wellbeing and causation; use the concept of indigeneity as an entry point for the analysis of diverse subjects that may hold some indigenous quality; and nurture relationships where knowledge boundaries are being crossed and where the co-production 
of meaning is happening.

\section{Opportunities for technical innovation: What is relevant to evaluation in Aotearoa New Zealand and the Pacific}

When the 2030 Agenda for Sustainable Development was endorsed at the UN by more than 150 countries, including all Pacific countries and Aotearoa New Zealand, the stated overall aspiration was to eradicate poverty and hunger globally. With 17 goals, 169 targets and (as of March 2016) about 230 indicators, the technical aspects of tracking the implementation of Agenda 2030 are huge, matched only by the structural changes in mainstream economic systems, which I will not discuss here (Fukuda-Parr, 2016).

The SGDs aim to address the unfinished business of the first set of global goals and targets set to eliminate poverty and hardshipthe Millennium Development Goals (henceforth the MDGs). The MDGs were eight goals set in 2000 with arguably measurable targets and clear deadlines (2015) for improving the lives of the world's poorest people. It was considered by some to be an aspirational approach to dealing with global poverty, but it also signalled a shift in international development by setting up "measurable targets and deadlines" to tackle poverty and hunger globally. Pacific countries (and many non-government organisations) were somewhat sceptical and thus relatively slow in adjusting to the ways in which the MDGs transformed the delivery of aid. However, after 15 years the Pacific could report on the progress of each country against each Goal, as well as how the region reported against each Goal (Pacific Islands Forum Secretariat, 2015).

One feature of the 17 SDGs is that there is considerable overlap. For ease of comprehension the goals can be grouped in several ways. The former UN Secretary General, Ban Ki-moon, worked with four clusters_-people, planet, prosperity, peace_-which partially coincide 
with my clustering. I focus on the primary orientation to people, places, work and humanity:

- SDGs pertaining to people: 1 poverty; 2 hunger; 3 health; 4 education; 5 gender equality

- SDGs pertaining to places: 6 water; 7 energy; 11 cities; 13 climate; 14 marine; 15 land

- SDGs pertaining to work: 8 decent work; 9 industry; 12 consumption

- SDGs pertaining to humanity: 10 equality; 16 peace; 17 partnership.

Behind these goals are the 169 targets and the 230 indicators, which is why attending to the details is critical. This is another mozzie bite moment where, without vigilant care and attention to detail, the smallest issue can undermine bigger arguments.

Multipurpose indicators of development have existed for some time. For instance, the multidimensional poverty index (Alkire \& Foster, 2011), developed by the United Nations Development Programme, the World Bank, and UNICEF to measure non-income based dimensions of poverty, is an indicator that can be used to cover SDG 2 (zero hunger), SDG 3 (good health and wellbeing), SDG 4 (quality education), SDG 8 (decent work and economic growth), and SDG 11 (sustainable cities and communities). Although it is useful to be able to use multidimensional indicators, in the Pacific there is a major problem getting the data in the first place. Why this is so is part of ongoing research among Pacific policy makers and statisticians, and further input from evaluators working with marginalised and small populations could be very useful.

While it is encouraging to have new indexes, even though 
there are no time series (which means the pace of change or progress against the goals cannot be measured), some targets still do not have appropriate indicators. For instance, one indicator for Goal 6 "Clean water and sanitation" is "tons of harvested product per unit of irrigation or percentage of wastewater flows treated to national standards" (Sustainable Development Solutions Network, 2012). In many semisubsistence economies in the Pacific, harvested products are not recorded, let alone those that benefit from irrigated water or wastewater; nor is this water necessarily being treated, nor are there national standards for treated water. So this indicator is out of scope for much of the Pacific on at least four dimensions. Yet clearly, while this cannot be measured, the indicator usefully draws attention to an aspiration to have water standards for irrigated water and wastewater, and to having an idea of how the size of harvests may vary with the amount and quality of irrigated water available. This is a useful aspiration and there is value in the indicator. However, it means that we need to recognise that, sometimes, actual numbers are less useful as representations of reality or progress, but more often serve the role of highlighting aspirational, and measureable, states. With this approach in mind, it is possible to see that the SDGs are not monitoring just for the sake of monitoring, but are also intended to change behaviour.

Another key technical feature of the SDGs worth noting is that all indicators are required to be disaggregated by sex, age, income, disability, ethnicity, economic activity, location, and migrant status. To complete this work much is needed, including considerable capacity building, new data sources, new data collection methods, and annual monitoring.

These technical features are important for evaluators because they signal two major differences between the SDGs and the MDGs: the SDGs provide an opportunity to respond in an integrated way to urgent global problems; and the SDGs are universal, so all countries 
are obliged to do something to achieve them, including Aotearoa New Zealand. At some time the New Zealand Government will need to report on our progress towards the SDGs, but questions remain unanswered: Who will do this? What data will be used? How will the data be disaggregated? and How will it be interpreted?

I would like to see evaluators, specifically those working on issues of poverty, inequity, and injustice, join with researchers and take the opportunity to contribute to the development of innovative indicators. Standard indicators will need to be provided, but we will also need indicators that are attentive to issues of diverse world views and can assist in dealing with attribution problems of impact evaluations with small sample sizes selection bias and other perennial problems in impact evaluation. It is important to keep our eyes on these indicators because they are part of the machine by which the aspirational goals and targets of the SDGs will be met.

Numbers and indicators are especially inadequate in less developed countries, but the paradox is that less developed countries like those in the Pacific need them the most because funders "pay for results" (Birdsall, Savedoff, Mahgoub, \& Vyborny, 2012, p. 6). This calls for meticulous interrogation of the numbers, asking who saw what, and under what conditions. Unfortunately, unsuitable numbers (as in our water example) still matter, so we need to develop other means to supplement such numbers, because 'counting', or quantification, is at best only a partial means of knowing anything. At worst, quantification carries a 'quiet power' that leads to governing human behaviour. We need to be wary of the seduction of quantification but not intimidated by the practices of quantification (Merry, 2016).

There will be a data revolution around the SDGs and it will be interesting to see how this is driven, resourced and assessed (Sustainable Development Solutions Network, 2015).

This is significant for Aotearoa New Zealand, both as a country 
and as a major development partner in the Pacific. The 2015 highly regarded Organisation for Economic Cooperation and Development Assistance Committee (OECD DAC) Peer Review of Aotearoa New Zealand was clear that we had to

raise the ambition of [New Zealand's] policy coherence for sustainable development agenda. This would be in line with the expanded and universal agenda of the Sustainable Development Goals from 2015. (OECD, 2015, p. 15)

The first recommendation was to urge Aotearoa New Zealand to commit to the SDGs by establishing a "prioritised, medium to long-term agenda to further promote policy coherence in areas with potential development benefit" (ibid).

This is the mozzie bite for Aotearoa New Zealand. Although we are a high-income developed country with reasonable systems for social and economic planning, we can still wake up in the morning and feel the mozzie bite-that sharp feeling that can lead to other ailments as we learn about the detail of problems: the detail of people sleeping on the streets, in cars, or crowded into substandard homes; the detail of how the casualisation of work is the new norm for many young people, and ageing ones; and the detail about the intimately linked consequences of these problems in our daily, social, and professional lives.

My point is that to ensure the aspirations behind the SDGs are given some chance of success, we must take metrics seriously, not naively. In the next few years we can contribute to the indicators as universal aspirational goals, and the best way to do that is using contextual literature, qualitative and quantitative field work, and time in the 'field' implementing carefully constructed and ethical sample surveys.

\section{Relationship between evaluation and research: Theory,}




\section{quality assurance, and ethical practice}

Finally, I want to argue that there are three key differences between research and evaluation: the place of theory, the nature of quality assurance, and moderation of ethical practice. These three differences became evident in a recent project that I have just completed. For the purposes of this presentation I will focus on the latter two.

In 2016, along with three other Pacific women scholars, I completed a Scoping Study on Gender Research in the Pacific for the Pacific Women Shaping Pacific Development Programme funded by the Australian government (Underhill-Sem, Chang Tung, Marsters, $\&$ Pene, 2016). In the time we had available and using standard practices for identifying scholarly research, we generated a bibliography of over 400 citations (published in peer-reviewed journals between 2004 and 2014) and produced an annotated bibliography of 135 articles. There was considerable appreciation from policy makers in the Pacific for this database. We, however, considered that it was just the start of a larger, more systematic process of finding relevant research. There was considerable disquiet among us over 'research-type' work that was not included, such as unpublished $\mathrm{PhD}$ and MA theses, as well as submissions to major national and international commissions and substantive impact evaluations.

In the workshop that followed we had frank discussions that eventually centred on the varied nature of quality assurance and the loose moderation of ethical practice. There was recognition both by policy makers and consultants who had done evaluations that there is often a critical gap between what the client wants-its political palatability - and what the evaluator has found. Sometimes there were processes by which findings considered disagreeable to the client were confidentially transmitted in full; other times, where the findings were unpalatable, findings were revised to be more compatible.

I am not entirely sure of the processes of quality assurance for 
evaluation in Aotearoa New Zealand, but in the Pacific my experience has been that much rests on the credibility of the chosen consultant. In scholarly research, as many will know, the controversial but conventional process of quality assurance is through publication in peer-reviewed journals. This is not failsafe, but it is a useful process, especially in journals with a clear process of quality assurance; that is, double-blind reviewing, where neither the reviewer nor the author are known to each other. The anonymity of this process, combined with a generous approach to reviewer comments, provides for a constructive learning process for all involved.

Another clear difference between evaluation and research is in the different approaches to ethical review processes. Scholarly research that involves the collection of data from human subjects is required to meet the basic ethical requirements of the research institution. In addition, there are usually clear guidelines about research practice. Researchers must gain ethical approval from university ethics committees to ensure there is informed consent, that researchers understand that they must 'do no harm', that participants are accorded appropriate privacy, and that there are no conflicts of interest. Although there are ongoing arguments between ethicists of absolutist and relativist persuasions, and 'ethics creep' is a real concern (see Haggerty 2004), fundamental to ethical behaviour is the nature of relationship building and trust.

This takes us back to the concept of indigeneity. But how do we know that the flexibility of the research process still adheres to the basic principles of ethical practice? And, moreover, what are the processes for calling out what someone would see as unethical research? "Active cynicism or intentional evasion" (Banks \& Scheyvens, 2014, p. 171) are inevitable, but this attitude needs to be moderated by the recognition that researching other people is an intrusion into their lives and there is power in one's privilege as an evaluator or researcher. 


\section{Conclusion}

I have argued here that addressing development problems in the Pacific requires urgent attention to diverse ways of knowing. This is the progressive part. Next I have argued that although the SDGs promise much and offer opportunities for developing appropriate indicators, there are also important technical challenges to meet. Lastly, evaluations in the Pacific need to pay attention to the small sample size issue, which requires, among other things, transparent ethical practices. This is where it connects to scholarly research.

Addressing longstanding and emerging development problems in the Pacific requires an interlinked approach that is grounded in context, animated by indigeneity, and cognisant and agile enough to accommodate diverse world views. The SDGs are on the horizon, and getting the metrics rights will bode well for development assistance. It will also enable civil society and marginalised citizens to hold duty bearers to account. There is room for innovation in developing indicators for Pacific countries—all of which are short on capacity and where small sample size evaluation and attribution problems prevail.

Finally, ethical guidelines in evaluations are critical, as is ethical practice. The challenge is to ensure that good ethical practice is linked to good-quality evaluation, and vice versa. The inequalities and impoverishment that are growing in Aotearoa New Zealand and the Pacific will not fade away, even with innovative approaches to indicators. Evaluators have a role to play in addressing the pressing issues of structural change. Like mozzie bites in the morning, we cannot ignore them or the consequences might surprise us, because small things can be potent - in both tragic and creatively progressive ways. 


\section{Note}

1 Ngāti Toa were 2014-2017 iwi-in-residence at Te Papa.

\section{References}

Alkire, S., \& Foster, J. (2011). Counting and multidimensional poverty measurement. Journal of Public Economics, 95(7), 476-487.

Banks, G., \& Scheyvens, R. (2014). Ethical issues. In R. Scheyvens (Ed.), Development fieldwork: A practical guide (pp. 160-186). London: Sage.

Bennett, J. A. (2015). Oceanian journeys and sojourns: Home thoughts abroad. Dunedin: Otago University Press.

Birdsall, N., Savedoff, W. D., Mahgoub, A., \& Vyborny, K. (2012). Cash on delivery: A new approach to foreign aid. CDG Brief. London: Centre for Global Development.

Fukuda-Parr, S. (2016). From the Millennium Development Goals to the Sustainable Development Goals: Shifts in purpose, concept, and politics of global goal setting for development. Gender \& Development, 24(1), $43-52$.

Haggerty, K. D. (2004). Ethics creep: Governing social science in the name of ethics. Qualitative Sociology, 27(4), 391-414.

Merry, S. E. (2016). The seductions of quantification: Measuring human rights, gender violence, and sex trafficking. Chicago, IL: University of Chicago Press.

OECD. (2015). New Zealand - DAC Peer Review of Development Co-operation 2015. Retrieved from http://www.oecd.org/newzealand/ peer-review-newzealand.htm

Pacific Islands Forum Secretariat. (2015). Pacific regional MDGs tracking report. Suva, Fiji: Pacific Islands Forum Secretariat. Retrieved from http:// www.forumsec.org/resources/uploads/embeds/file/2015\%20Pacific\%20 Regional\%20MDGs\%20Tracking\%20Report.pdf

Radcliffe, S. A. (2015). Geography and indigeneity I: Indigeneity, coloniality and knowledge. Progress in Human Geography, 41(2), 220-229. 
Sustainable Development Solutions Network. (2012). Indicators and a monitoring framework launching a data revolution for the Sustainable Development Goals. Retrieved 17 March 2017 from http://indicators. report/goals/goal-6/

Sustainable Development Solutions Network. (2015). Indicators and a monitoring framework for the Sustainable Development Goals: Launching a data revolution for the SDGs. Paris, New York, New Delhi: Sustainable Development Solutions Network.

The World We Want. (2015). About. Retrieved from https://www. worldwewant2030.org/post2015-about

Underhill-Sem, Y. (2003). Children of the night cleaners. In P. FairbairnDunlop \& G. Makisi (Eds.), Growing up Pacific Island in New Zealand (pp. 65-74). Palmerston North: Dunmore Press.

Underhill-Sem, Y. (2016). Critical gender studies and international development studies: Interdisciplinarity, intellectual agility and inclusion. Palgrave Communications, 2(16012), 1-5.

Underhill-Sem, Y., with Chang Tung, A., Marsters, E., \& S. Pene. (2016). Gender research in the Pacific: 1994-2014: Beginnings. Suva, Fiji: Pacific Women Shaping Pacific Development.

United Nations. (2015a). About major groups and other stakeholders. Retrieved from https://sustainabledevelopment.un.org/majorgroups/about

United Nations. (2015b). High-Level Political Forum. Retrieved from https:// sustainabledevelopment.un.org/hlpf

United Nations. (2015c). Transforming our world: The 2030 Agenda for Sustainable Development. Retrieved from https://sustainabledevelopment. un.org/post2015/transformingourworld 


\section{The author}

Associate Professor Yvonne Te Ruki Rangi o Tangaroa UnderhillSem, Development Studies, School of Social Sciences, Faculty of Arts, University of Auckland. Yvonne has been involved as a scholar, a consultant, and an advocate in research and evaluation in development throughout the Pacific and internationally. Her research expertise is in critical gender analysis in development; feminist political ecology; critical population geography; and interdisciplinary development for social justice in the Pacific.

Email: y.underhill-sem@auckland.ac.nz 